\title{
VOLVER A LA TERNURA
}

Elizabeth Bazán Gayoso*

"Bajo el cielo de la ternura derribaremos la selva del odio bajo el gran cielo de una fe construiremos la casa bumana"'

\section{RESUMEN}

La ternura es un potencial afectivo inherente a la estructura humana, fundamental en el proceso de crecimiento personal, familiar y social. Su presencia temprana en la relación materna se reflejará posteriormente en una personalidad sana, capaz de afrontar los desafíos y conflictos. La ternura como cuidado nos remite a lo concreto de la vida y es una alternativa ante la dureza de corazón y la indiferencia social. Su fuerza histórica y profética es capaz de transformar las relaciones interhumanas. Tenemos la responsabilidad de comunicar esta ternura por fidelidad a nuestro ser y al ser de los otros y está en nuestras manos volver a ella, recrearla.

PALABRAS CLAVE: Ternura, cuidado, relaciones interhumanas, fuerza profética, fuerza histórica, recrear.

\section{RETURN OF TENDERNESS}

\begin{abstract}
The tenderness is an inherent affective potential element inherent to the human structure, fundamental in the personal, family and social development process. Its early presence in the early maternal relationship will be reflected subsequently in a healthy personality, capable to face challenges and conflicts. The tenderness as a care leads us to the concrete of the life and is an alternative response in view of the hearth hardness and the social indifference. Its historic and prophetic hardness is capable to transform interhuman relationships. We have the responsibility to communicate this tenderness by fidelity to ourselves and others. It is in our hands to return into it, recreate it.
\end{abstract}

KEYWORDS: Tenderness, care, inter human being relationship, prophetic strength, historic strength, recreate.

*Religiosa del Sagrado Corazón. Licenciada en Filosofía, Literatura, Ciencias Religiosas. Bachiller en Ciencias Humanas. Doctora en Educación por la UNIFÉ. Docente Principal en la Universidad Femenina del Sagrado Corazón, donde tiene a su cargo los cursos de Teología II y Doctrina Social. Se ha desempeñado como Jefe del Departamento de Filosofía y Teología, y ahora Coordinadora del Doctorado en Educación en esta misma Casa de Estudios.

${ }^{1}$ Adaptación de La maison humaine- Martin Gray. París 1984. Martín Gray, judío polaco, perdió a su familia en la 2da guerra mundial. En 1970 su esposa y cuatro hijos perecen en un incendio forestal. Ha consagrado su vida a la protección de la naturaleza. 


\section{Introducción}

La violencia amenaza hoy al mundo de manera exacerbada y en formas diversas tanto físicas como psicológicas; afecta de manera especial a las mujeres, niños, ancianos y personas más desprotegidas. Su presencia a veces se pretende justificar aduciendo que pertenece a la energía agresiva del hombre en la conquista de sí mismo y de la naturaleza. En realidad la afectividad humana es una gran riqueza, inclusive la emoción de la ira y la cólera no es una emoción necesariamente negativa, porque su energía puede canalizarse, modificarse a través de la maduración y el aprendizaje. La violencia es un comportamiento aprendido orientado a hacer daño a otros.

Aquí se aborda el tema de la ternura como un potencial afectivo inherente a la estructura humana, fundamental en el proceso del crecimiento personal, familiar y social. Se destaca la necesidad de la ternura en las relaciones interhumanas, así como con la creación y las diferentes formas de expresión.

Está centrado más en los aspectos psicológicos e intersubjetivos, pero considero que la ternura se puede ampliar a los ámbitos social y político, a través del concepto de reconocimiento tal como lo trabaja Axel Honneth en su artículo "Reconocimiento y obligación moral".

La experiencia humana de la ternura, como estado emocional inicial está vinculada al proceso del crecimiento de la vida del ser humano, y ha hecho posible lo que somos. El déficit de ternura deja sus huellas en la persona.
El cuidado como expresión de la ternura, y lo que da sentido a la existencia, nos remite a lo concreto de la vida. El ser humano está vinculado existencialmente a otros y necesita experimentarse en comunión con otros. La ternura como invocación desde el otro nos recuerda que no es sólo un comportamiento para la intimidad, no se reduce al ámbito privado. Pueblos y naciones tendrían que revisar si este elemento revelador de lo humano está presente en sus leyes, decisiones, estilo de relaciones y su vinculación con la naturaleza.

La ternura como fuerza histórica capaz de motivar y transformar la sociedad, nos llama a un compromiso serio con la realidad, porque la destrucción de la vida y del planeta está hoy en las manos del hombre y urge volver a la ternura que no es sensiblería, sino decisión de amar y amarnos responsablemente.

La ternura tiene en la espiritualidad bíblica su raíz profunda y en Yahvé, su manantial. Toda la historia del pueblo, desde el cual nace nuestra fe, se centra en la ternura, amor y fidelidad de Yahveh quien lo acompaña por siempre en su camino de libertad y triunfo sobre el temor. Desde esta experiencia bíblica el hombre recibe la promesa de cambiar su corazón de piedra por un corazón de carne. Este corazón de carne tiene que ver con el corazón de Dios.

Relacionado con este tema está el del profetismo de la ternura. Se plantea la ternura como evocación de una realidad alternativa para el mundo, como resistencia al egoísmo, al mal, a la dureza 
de corazón, a la rigidez e indiferencia social. Se hace referencia a la cosmovisión andina y nativa de la naturaleza, de la que podemos aprender su comprensión global, totalizante y dinámica: hombre, Dios, naturaleza. Lo profético está constituido por gestos, no sólo palabras, cuestiona la manera de mirar, de tocar a otros, de acoger, de situarse, escuchar y valorar. Con la ternura el amor echa raíces, se hace sólido, algunos hogares testimonian un hermoso modo de llevar la vida humana, de promoverla y sostenerla.

El último tema intenta dar unas pistas para promover el potencial de la ternura. Es ante todo un aprendizaje, el hogar influye tempranamente en el desarrollo emocional del niño. Estamos desafiados a desarrollar las emociones positivas; la escuela contribuye en la educación emocional, y hay espacio para acciones muy concretas.

Promover la ternura pide una revisión del lenguaje que usamos de la manera como nos relacionamos, de las actitudes de cada día. Se trata de formar el corazón en la ternura. Jóvenes y adultos podemos recrear la ternura, despertarla si está adormecida y aprender a expresarla. La intención de este trabajo es mostrar que se tiene que recuperar la ternura para dinamizar el proceso de desarrollo de lo humano a nivel personal y social y como alternativa a la violencia, como llamada a que renazca la ternura en nuestra sociedad maltratada.

\section{Experiencia Humana de la Ternura}

La ternura es un estado emocionalmental positivo, satisfactorio, en el que intervienen emociones, expectativas, necesidades, y actitudes. Es una relación cuya resonancia repercute en las fibras íntimas del ser, no es simple respuesta a sensaciones.

Es una necesidad emocional central, vinculada al crecimiento humano y se la requiere como experiencia vital desde el seno materno, porque allí el niño que está al nivel de la sobrevivencia se nutre de la ternura de la madre. Es su soporte desde la gestación, protege su salud física y psicológica; asimismo favorece el desarrollo del lenguaje y del pensamiento como respuesta a los gestos maternos de ternura.

Se sabe que a la cuarta semana el niño escucha ya las diferentes voces: el grito o enojo lo contrae, la voz de cariño, lo apacigua. Cuando no ha podido satisfacer sus necesidades emocionales, algo en él está molesto, y actúa con cólera hacia los demás, pero más aún, la carencia de ternura puede llevarlo a ser pasivo, desamparado, manipulable.

Cuando falta la ternura, queda en el ser humano un "esquema" disfuncional emocional de carencia o abandono y el consiguiente comportamiento de inestabilidad y vulnerabilidad. Este esquema mental adquirido lo constituyen recuerdos, emociones, sensaciones corporales y cogniciones, que como experiencia temprana pueden permanecer en la persona y desencadenar comportamientos disfuncionales en la vida adulta y un estilo poco sano de afrontar los conflictos y situaciones difíciles. 
Helga Auer en su libro "Psicología Humanistica" (1997) dice que el déficit de ternura surge casi siempre en los primeros meses de vida, a causa de una falta o privación de estimulación emocional persistente. Como consecuencia se puede dar más tarde reducción de energía para asumir iniciativas, un sentimiento crónico de vacío, falta de sentido, dificultad para comprender los propios sentimientos, ser fácilmente manipulables y captables por fanatismos.

Según Erickson (1956) el niño aprende a confiar a partir del cuidado de su madre que responde a sus necesidades vitales; al darse cuenta que es querido va construyendo una actitud positiva hacia el mundo social, sabrá dar, porque la relación positiva produce felicidad, lo contrario, lo volverá hostil e impredecible.

\section{Ternura-Cuidado.}

El cuidado es la expresión básica de la ternura. Es el ethos fundamental de lo humano, le confiere sentido a la existencia. Ontológicamente el cuida-do subyace a todo lo que el ser em-prende, porque el ser humano tiene necesidad de cuidado para existir, y una manera de estar en el mundo es cuidar, ayudar a crecer. Sin cuidado dejamos de ser humanos. (Boff L. 1999)

Martín Heidegger (1927) también desde su filosofía de la existencia expresa que una de las características fundamentales de la existencia del hombre es el "cuidado" o ternura. El hombre es cuidado, lleva en la estructura esencial de su existencia la ternura, que es un fenómeno estructurador de su personalidad. El cuidar es una acción constructiva fundamental para que el ser humano pueda subsistir en el ser, para que pueda ser auténticamente lo que es, y para que pueda alcanzar niveles de perfección existencial.

El cuidado, "sorge" en alemán, tiene el sentido latino de interés, atención, solicitud, preocupación por el hombre, entrega, ternura, esforzarse solícitamente por alguien en respuesta a las necesidades del otro El cuidado, en tanto que anticipación nos habla de lo que todavía no es y por tanto necesita de los otros. Ser uno para otro.

Pueden darse modos deficientes de cuidado como prescindir los unos de los otros, pasar el uno al lado del otro, no interesarse los unos por los otros. En lo cotidiano esta solicitud puede ser sustitutivo- dominante o anticipativaliberadora. Esta última sería una ayuda al otro para hacerse transparente en su cuidado y libre para él. Como dice Heidegger (1927) el ser humano no puede avanzar hacia su plenitud personal, sino proporcionándose a los otros y recibiendo de ellos.

El cuidado pide acompaña-miento, caminar al lado de, afrontar asertivamente las diferencias, cuidar los procesos, "perder el tiempo", compartir desde dentro, rescatar lo positivo de cada uno acogiendo la propia vulnerabilidad.

Ternura es pues, hacerse cargo de los problemas de la otra persona y compartirlos. Es compromiso de donación, de afecto que busca la alegría del otro a través de detalles en apariencia pequeños. Ser tierna/o es ante todo una 
actitud afectiva interior que no se limita a las manifestaciones externas, que pueden ser puramente convencionales. Nace de la comprensión de la personalidad del otro u otra.

Entre las frases célebres de Fernando Savater encuentro ésta referida a la ternura, que nos invita a revisar nuestra manera de amar: "el amor sin ternura es puro afán de dominio y autoafirmación hasta lo destructivo y la ternura sin amor es sensiblería incapaz de crearnada”.

Boff, L (2003) explicita algo semejante, que sin solicitud y cuidado, el ser humano no sobrevive. Esta solicitud representa una relación amorosa con la realidad y además donde hay solicitud, ternura, desaparece el miedo, origen secreto de la violencia, y se promueve una cultura de paz.

\section{Ternura- Apertura: Invocación desde el otro}

La ternura no se reduce al ámbito privado; la sociedad la necesita en las relaciones, porque ella tiene la capacidad de reconstruir el mundo y de facilitar su conocimiento a partir de los lazos afectivos. Es una manera de comulgar unos con otros y de conectarnos con la realidad. A pesar del marcado individualismo que tiende a absorberlo, el ser humano está vinculado existencialmente a otros, y necesita experimentarse en comunión con otros, como sucede en nuestra corporalidad y en la misma naturaleza, cuyas relaciones de reciprocidad hacen la unidad. La sociedad para su unidad también reclama esta ternura hecha de relaciones delicadas, respetuosas, cuidadosas, armoniosas, valorando la diversidad cultural e individual.
Esta dimensión humana aparece como clamor cuando la persona reconoce su fragilidad, ve de cerca el odio y experimenta cuán fácilmente se convierte en agresor. Lanssiers H. (1998) decía que ver al hombre con hambre, enfermo o maltratado puede provocar indignación, cólera, pero también inclinar el corazón a la ternura, al cuidado, a involucrarse en el dolor humano. Lo que significa que cuando se mira a un hombre o a una mujer al rostro se es capaz de reconocer en él a un hermano ohermana.

"Somos tiernos, nos dice Restrepo L. (1997) cuando abandonamos la arrogancia de una lógica universal y somos afectados por el contexto, por los otros, por la variedad de seres y especies que nos rodean... Somos tiernos cuando reconocemos nuestros limites y entendemos que la fuerza nace de compartir con los demás el alimento afectivo. Somos tiernos cuando fomentamos el crecimiento de la diferencia, sin intentar aplastar aquello que nos contrasta. Somos tiernos cuando abandonamos la lógica de la guerra, protegiendo los nichos afectivos $y$ vitales para que no sean contaminados por las exigencias de funcionalidad y productividad a ultranza que pululan en el mundo contemporáneo."

Carlos Medina abre este potencial al espacio social "La ternura como sentimiento convoca lo colectivo, la búsqueda del bienestar común, la preocupación por el otro y por sí mismo, reconoce las virtudes y dificultades y las carencias, identifica las más sutiles diferencias y las respeta; la ternura es la expresión sentida del afecto en una época de crisis de valores en la que la vida misma está en juego" (II Congreso Regional de Educación Infantil. Colombia 1999)

El mundo herido por guerras, miseria, violencia, abandono, indife- 
rencia reclama la ternura, invoca ternura y recuperar humanidad. La ternura no es sólo comportamiento para la intimidad, ni sólo interpersonal. Pueblos, naciones enteras tendrían que revisar si este elemento revelador de lo humano inspira leyes, decisiones, estilo de relaciones internaciones y su vinculación con la naturaleza. Porque vivimos un déficit de ternura que es una necesidad básica para todos y para toda la creación; el mundo languidece, sus propias conquistas destruyen el espacio donde pretende encontrar bienestar.

La ternura a nivel social es no violencia activa. No es pasividad. Es acción de alto contenido humano que desarma al agresor y le refleja su rostro inhumano, le denuncia y avergüenza

La modernidad atraviesa nuestra vida de inmediatez y superficialidad, afectando nuestras energías, motivaciones, aspiraciones, estados de ánimo y relaciones. Benjamín González Buelta B. (2010) califica nuestro mundo de "líquido", la realidad fluye bajo nuestro pies; valores, instituciones, todo pierde consistencia. Ciertamente se puede constatar que ahora el cuidado por los otros es débil, falta lucidez para percibir necesidades, búsquedas, inquietudes de las personas con quienes vivimos y así descuidamos el hacernos cargo de los otros. En la relación de pareja a veces se despierta cuando la relación ya perdió calidad, el entorno se ha vuelto inexpresivo, aburrido y entonces aparece la tentación de huir a otros espacios y presencias. Se olvidaron los pequeños y esenciales gestos de ternura, que cultivan la intimidad y fortalecen la fidelidad.

\section{La Ternura: Fuerza Histórica}

La ternura no es pues sensiblería, es compromiso serio y decisión de amar y amarnos responsablemente en las diferentes dimensiones de la vida. Se tiene que practicar en fidelidad a lo real y sus necesidades. Como valor moral tiene fuerza histórica capaz de motivar y transformar la sociedad.

El hombre ha enfatizado hasta ahora el triunfo de la fuerza, del poder, de la eficacia y el control como medios para cumplir el encargo de administrar la tierra (que confundió con dominarla) Una racionalidad unidireccional y satisfecha de sí, le ha dado logros, pero lo somete a su dominio. Hoy sin embargo le muestra que no es único en su camino de vida y creación y que está llamado a volver a la ternura para recuperar un nuevo alumbramiento: llevar a los indefensos, necesitados, víctimas del olvido o la violencia hacia una vida plena.

El cuidado es intervención y prevención. Hoy los servicios de salud para los niños son insuficientes al interior del país. Según datos del Ministerio de Salud el $47.2 \%$ de los niños peruanos entre 6 y 36 meses padece anemia. La ONU al 2010 calcula que cada año unas 800,000 personas son víctimas del tráfico humano en el mundo. De las mujeres y niños el $70 \%$ son obligados a prostituirse; es un crimen, que entre otros, reclama una alternativa en el mundo. Así mismo el 48\% de las mujeres de Lima y el 61\% en el Cusco reporta haber sufrido violencia física por parte de su pareja. Entre el 2003 y el 2005 se dieron 265 casos de feminicidio o crimen con la mujer por razones de género. Otro 
grupo humano frágil es el adulto mayor: en el 2002 se encontró que el 24\% de adultos mayores sufrían maltrato de forma sistemática.

Otros retos, a nivel macro, el desastre radiactivo en Fukushima- Japón 2011 ha dado la alarma del "cuidado", ternura que necesita la humanidad; su derecho a ser protegida de la destrucción. Crece asimismo en el mundo la conciencia del cuidado y cultivo de la justicia, la paz y la integridad de la creación, ante las señales de alto riesgo y agotamiento del planeta, y la necesidad de recuperar la vida para las generaciones futuras ${ }^{3}$.

Es un imperativo establecer relaciones ricas en humanidad, en ternura. Si las personas la necesitan el hombre es responsable de vivirla. Es el reconocimiento de la dignidad de la persona por alguien que respeta y ama esa dignidad. No es un plus en la relación sino la condición de ser humanos, no se puede decir de ella "da lo mismo vivirla o no". No sólo la necesita el ser humano en la edad temprana, es un modo de ser hombre o mujer que vamos descubriendo como un deber ser de orden práctico que da sentido a la vida humana.

\section{La Ternura en la Espiritualidad Bíblica}

La Sagrada Escritura centra la vida en el corazón, amar es la forma de conocimiento más profundo. La ternura en la espiritualidad bíblica se atribuye a Yaveh. El proceso de conocimiento que el pueblo hebreo hace de El, les va revelando una persona que conoce el corazón del hombre, es cercana, dialogante y ama con ternura. Es un Dios compasivo, misericordioso tardo a la cólera y rico en perdón, es paciente y grande en amor y en verdad. El Señor es con los que lo honran como un padre con sus hijos; pues sabe de qué estamos hechos.

Se ha trabajado muy poco este corazón de Padre, que asegura a menudo: "Yo voy contigo; voy a cuidarte por dondequiera que vayas...no voy a abandonarte". Esta experiencia de Dios se necesita ahora, porque el Dios que se ha mostrado ha sido a veces opuesto a la auténtica invocación de ternura que la misma naturaleza humana pide para desarrollarse y alcanzar plenitud. No puede haber contradicción entre la búsqueda de felicidad que todo hombre hace como su fin y Dios creador que conduce la historia hacia su plenitud. El mismo pueblo hebreo se compara con otros y se pregunta "¿Hay algún pueblo que haya oído como tú has oído la voz. del Dios vivo? Este Dios también dice: "Te uniré a mi en la ternura, el amor y la fidelidad". Oseas 2,21.La experiencia del creyente es que este Dios tierno y compasivo no abandona y "a todas las obras alcanza su ternura”. Salmo 145: 9

El Deuteronomio pide al pueblo recordar que en el desierto Yaveh los llevaba como un hombre lleva a su hijo, a todo lo largo del camino, por lo tanto no tienen que temer. El temor es el sentimiento que domina en el mundo y tenemos que apropiarnos de esta ternura

${ }^{3}$ Cabe resaltar la tarea heroica de cuidado, de 70 operarios escogidos para controlar la contaminación radiactiva en Fukushima. Trabajan por tunos de 15 minutos, cada dos horas, con la mirada puesta en el radiador que les cuelga del cuello y les indica cuándo deben abandonar el área. Esa es su rutina. Tokio. Comercio 18-04 2011 
y compasión para crecer en confianza, desanudar temores, repliegues, tristezas que ofuscan e impiden tener una presencia proactiva en la familia, instituciones y aportar creativamente a la sociedad.

Jesús no teme escandalizar llamando a Dios Padre, reconociendo que viste de hermosura a los lirios y cuida los pájaros del campo. El mismo exalta la sencillez y ternura del niño y expresa su ternura a la mujer, al pecador y al desvalido. Manifiesta el valor del amor humano, del goce; nutre la esperanza, hace ver que cuando más crece la persona, más grande es Dios.

Pablo, apóstol, desde su experiencia, también evangeliza presentando al Padre lleno de ternura que siempre consuela a la persona para que pueda consolar a otros. 2 Cor 1:4. El apóstol Juan también da testimonio del mensaje que escuchó de Jesús desde el principio, que Dios es amor y creer en Jesús es amarnos unos a otros; pero este mensaje no se ha tomado muy en serio, ni tampoco el grito de Jesús que atraviesa la historia, campos, rincones de pobreza, hospitales y orfelinatos: "Siento compasión de la gente...no tienen qué comer, no quiero despedirlos en ayunas, no sea que se desmayen en el camino"

El Padre Lanssiers (1998) quien trabajó más de 20 años en la Cárcel de San Juan de Lurigancho, amó, sufrió y fue allí samaritano, escribió que "la inmensa ternura de Dios es el océano que nos alimenta y el aire que permite vivir"; tal vez no nos asomamos a este océano.

El mensaje permanente para el hombre es "Cuidar": "Cuida tu corazón, porque de él brota el manantial de la vida" Proverbios 4: 21. Se trata de abrir el corazón a lo universal, hacerlo fuerte, libre, profundo, fiel. Liberarlo de lo que empequeñece y esclaviza; con un amor expansivo, tierno, gratuito que embellece la relación y a las personas que se sienten amadas con amor delicado. Desde la experiencia bíblica el hombre recibe la promesa de recibir un corazón nuevo, de cambiar su corazón de piedra por un corazón de carne. Este corazón de carne tiene ver con el corazón de Dios. Ezequiel, 36:26.

Cuidar el corazón es procurar vivir desde él, contemplar, escuchar, acoger, bajar al bien profundo de las personas y de los acontecimientos para tocar lo auténtico. Supone ordenar los afectos, "decantarlos", estar atentos a filtrarlos para hacer transparentes y saludables las experiencias que se viven.

La formación del corazón requiere un largo proceso, hasta ser el corazón de Dios en el mundo...Juan Pablo II decía a los jóvenes de Francia: "tener un corazón sensible nos hace vulnerables, por eso algunos tienen la tentación de rehuirlo endureciendo el corazón". Muchas veces olvidamos que no somos islas, sino solidarios por naturaleza, y que nosotros bajamos o subimos el nivel de amor en el mundo.

\section{El profetismo de la ternura}

La ternura es evocación de una realidad alternativa. De ahí su sentido profético. El Espíritu de Dios que dinamiza la creación y está en la entraña del mundo, es el generador de ternura, de la poderosa energía de resistencia al 
egoísmo, al mal, a la rigidez e indiferencia social. El Espíritu nutre la acción humana de su aliento de vida, gozo, paz y no violencia.

Desde una perspectiva antropológica, la cosmovisión andina de la naturaleza, puede enseñarnos al respecto, porque es una concepción integral del pensamiento humano. Es una penetrante comprensión global, multidimensional, holística y dinámica: Hombre- naturaleza- Dios. Igualmente totalizante de las dimensiones de la existencia: pasado, presente, futuro; de los elementos de la naturaleza: tierra, agua, aire, plantas, animales, montañas. Vida-muerte; fiesta- dolor; resistenciaternura- comunidad. El espíritu que es vida lo anima todo. Esta comunión con la naturaleza es también propia de la cosmovisión nativa.

Lo profético está constituido por gestos, no sólo palabras, que abren los ojos a lo que es vida y proyecto auténticamente humanizador. La ternura expresa un modo distinto de ser y de amar. Cuestiona la manera de mirar, de tocar a otros, de acoger, de situarse, escuchar y valorar. Aporta un rostro humano a la relación.

Desde una lectura místico creyente, es una manifestación del Espíritu de Dios comprendido como amor-ternura, dinamismo relacional inclusivo que habita en la corporalidad humana y se comunica a través de signos del cuerpo. $\mathrm{Su}$ lenguaje dispone a vivir relaciones dignas, gratuitas, equitativas, recíprocas, capaces de transfigurar sufrimientos, temores, odios en gérmenes de vida $y$ esperanza; todo depende de la autenticidad y profundidad de los signos, señales o gestos de ternura, que impliquen a toda la persona en su donación a los otros.

La ternura es pues un movimiento en este proceso trascendente. No sólo abre a la existencia, posibilita el crecimiento en humanidad y la realización del sentido de la vida, sino que encamina hacia la comunión profunda con otros. Este dinamismo relacional también habita el cosmos en su profundidad y conecta toda la realidad con hondura, entra en el proyecto creyente de la solidaridad humana universal y plena.

Ante la racionalidad instrumental y la lógica de la modernidad, con sus características de utilitarismo, acumulación, increencia, violencia, que ponen a las personas y naturaleza en riesgo de reducirse a objetos, la ternura no puede limitarse a ser solo, una actitud, un comportamiento aislado, tiene que constituirse en una cultura enraizada en el interior de la persona y en sus relaciones, y construir a partir de ella nuevos espacios de convivencia, porque la ternura humaniza la existencia humana.

Nuestras sociedades modernas están marcadas por múltiples enfermedades, y sufrimientos, las personas ancianas piden cercanía, mujeres y niños viven muy solos, el hambre persiste en el mundo, las depresiones afectan a niños y adolescentes. A estos últimos la carencia de ternura los vuelve rebeldes, porque no la reconocen de la manera en que la necesitan, pero cuando reciben expresiones de ternura, que no siempre saben reclamar abiertamente, se alimenta su 
esperanza, crecen sus sueños, se alejan las evasiones. Por todas partes hacen mucha falta modelos vivos de ternura y cordialidad.

Hay hogares en los que la relación hombre- mujer testimonia la ternura, porque se da un cierto grado de serenidad, de paz en dicha relación. Se logra que la otra persona saboree la grandeza de saberse amada/o, estimada, respetada, tratada con cariño y cuidado. Al superar relaciones de "utilización" por la reciprocidad amorosa y delicada, ambos crecen en conciencia del propio valor, vivenciando el reconocimiento mutuo de la propia dignidad. Se podría decir que con la ternura las personas se sienten gratificadas en sus inseguridades, crecen en autoestima y son más seguras en su relación; por lo tanto los vínculos se ahondan, crecen en intimidad, se les facilita estar abiertos a la novedad, al gozo sereno del espíritu, a la comunión. Ser querido/a así es la mayor gratificación que puede recibir quien ama. Con la ternura el amor echa raíces, se hace sólido y profundo, es una manera de sostenerlo, porque el amor necesita cuidado y es decisión de cada día. Es un hermoso modo de llevar la vida humana, es un estilo de vida a promover $y$ sostener. "El misterio es lo más hermoso que nos es dado sentir" (Einstein) y la ternura es puerta abierta al asombro, como descubrimiento y admiración de la riqueza espiritual que encierra lo humano, uno mismo como ser humano.

Como Fortalecer el Potencial de la Ternura

La ternura es el lenguaje de la sencillez en un mundo complejo y violento y es posible generarla, porque el corazón es muy rico en energía positiva y la ternura tiene un amplio espacio en él. Sabemos que los recursos psicológicos positivos se aprenden y pueden desarrollarse a través de la experiencia. Los padres o personas que desempeñan el rol de cuidar al niño influyen tempranamente en su desarrollo emocional; la interacción positiva despierta un desarrollo socio afectivo saludable.

El entorno familiar influye mucho; las investigaciones revelan que cuando en la familia se expresan adecuadamente las emociones y se habla de ellas, los hijos aprenden a procesar sus emociones. En ambientes comunitarios donde se viven experiencias de afectividad positiva, los niños y adolescentes se van preparando para expresar sus emociones positivas y entre ellas la ternura, que muchas veces las personas adultas se resisten a expresar.

Se puede aplicar a la ternura lo que Seligman (2005) sugiere para desarrollar las emociones positivas: otorgarles atención, tener contacto físico, ofrecer señales de cariño que refuerzan la ternura, este contacto físico; para el bebé es fundamental. Dar espacios de juegos interactivos de manera que experimenten satisfacción, evitar prodigar el "no" fuera de situaciones en que se requiere poner límites, utilizar refuerzos positivos que gratifiquen logros, sin exagerar. Como vemos el desarrollo de la ternura y en general de las emociones positivas está conectado con la experiencia de felicidad que experimenta el niño, el adolescente y el adulto. 
La escuela tiene también una tarea muy valiosa en la educación emocional. Fernández Abascal (2009) habla de las buenas prácticas que se deberían fomentar en la escuela para que los niños sean felices; entre otras: espacios y tiempos para la felicidad, calma, diversión, clima de seguridad, creatividad, curiosidad, valoración de cada persona en sus virtudes, expectativas positivas, lenguaje positivo, relación con familias, organización flexible, de consenso, modelos positivos, etc. También motivar la atención del niño hacia el cuidado de la tierra, plantas, mascotas, ayudan a desarrollar los sentimientos positivos.

La acción educativa incluye todos los ámbitos del quehacer humano y es una permanente interrelación. Fundamentalmente se educa amando y con esa condición la educación resulta transformadora, hace crecer en humanidad. Es clave la concepción de persona que tenemos para actuar de una u otra manera. Magdalena Sofía Barat la consideraba llamada a desplegarse en todas sus dimensiones humanas, a abrirse a la verdad, al amor y a la libertad, por ello, centró su propuesta pedagógica en el amor. Decía a las educadoras: Tengan con sus estudiantes "firmeza y ternura". Corrijan sin quebrantar, ayuden sin sobreproteger, acompañen sin quitar libertad, comprendan sin invadir la intimidad. Tengan un corazón de madre para cuidar de cada una. Sólo así lograrán formar mujeres auténticas, cuya fortaleza es capaz de afrontar toda suerte de dificultades y cuya libertad sabe elegir una vida entregada, con sencillez a los demás. Invitaba a aprovechar cada asignatura para formar el espíritu y el corazón de las estudiantes. Insistía en la necesidad de un acuerdo perfecto entre todos los educadores para consagrar mucho tiempo a las estudiantes, seguirlas de cerca y aprovechar todo para educarlas. (UNIFE, 2009)

Pero, no sólo esto, la gestión de una institución educativa, cuando está atravesada por el amor, es en sí misma educadora. En el espíritu de la educación del Sagrado Corazón, esta gestión se centra en la persona, se construye viviendo la experiencia de comunidad, creando una visión compartida, potenciando y armonizando los carismas de las personas, abiertas a los demás y con visión de cambio permanente. Esto es una manera de vivir la ternura en la educación.

Toda profesión es un sistema abierto a la creación junto con otros, a la inspiración, a la calidez de la ternura; es posible hacer de ella un aporte humanizante de tolerancia, de concertación, diálogo e irradiación de gozo y esperanza.

Fortalecer la ternura supone una revisión del lenguaje que usamos, de la manera como nos relacionamos, de las actitudes que tenemos en el día a día, del ser que cultivamos.

Los jóvenes y adultos podemos recrear la ternura, despertarla si está adormecida y aprender a expresarla. Creo que en la entraña de la razón humana tiene su raíz el cuidado del alter humano, de allí se derivan obligaciones correspondientes a las necesidades humanas esenciales y la ternura es una de ellas. Los varones también tendrían que, desarrollar su sensibilidad para reconocer sus emociones como la 
empatía, la compasión, y aprender la práctica de la ternura al estilo materno. De hecho hay padres que hacen de madres y con su ternura logran responder a las necesidades de hijos pequeños. Pero no nos referimos sólo a una suplencia, es urgente y una necesidad que reinventen una relación emocional con sus hijos, de la que ellos mismos se privan. El aprendizaje cultural que han hecho los varones ha sido inhibidor de emociones, pero ellas están en su estructura personal y son su riqueza.
Tenemos que darnos a nosotros y a los otros la oportunidad para sacar lo mejor de sí mismos.

La formación del corazón en la ternura requiere cultivar la paciencia, el perdón, la compasión como hábitos del corazón. ¿Es coherente hablar de paciencia y ternura dada la realidad que vivimos? Para la prisa con que vivimos hoy y las expectativas acumuladas, no parece que el saber esperar, soportar, tener paciencia, sea un valor importante, sin embargo es lo que controla el ímpetu que destruye vínculos profundos. Pareciera ser que hoy se acaba la paciencia en los individuos, como en el país y en el mundo.

¿Qué supone ser pacientes desde la realidad? Reducir la velocidad de nuestras vidas, acciones y adiestrarnos a la serenidad, para impedir que la urgencia de las cosas nos arrastre hacia el torbellino de prisas que impida pensar, respirar. La paciencia no es pasividad, pide coraje y humildad.

Explicitar la ternura requiere superar prejuicios culturales como: "al hombre le corresponde la fuerza, la imposición", "los sentimientos delicados expresan debilidad" etc. Reconocer que en nuestra condición humana hay grandeza y fragilidad, nos sitúa más allá de todo juicio, y nos hace accesibles al impacto humano que viene del otro. La ternura "es dejarse hacer por el otro”, es activa y pasiva.

El clima familiar, institucional y social tiene que cuidarse, porque cuando las situaciones de pobreza, hambre, agresión, malos tratos, son extremas y persistentes, pueden sucumbir los 
sentimientos más nobles y positivos, debilitando las resistencias.

Muchos niños/as y jóvenes crecen en ambientes violentos que les dejan traumas y afectan su misma identidad. Abrirlos al aprendizaje de relaciones nuevas, de ternura y respeto, puede ir sanando y recuperando su ternura temprana o acogiendo aquella que no recibieron. Existe por todas partes un reclamo latente de acercamiento y proximidad que manifieste compasión, solidaridad, amorosidad. Hace falta alentar modos de relación más cercanos, cordiales, sinceros, acogedores, delicada ternura y calidez.

También sería interesante ir descubriendo la vinculación de la ternura con las decisiones políticas, económicas, sociales, religiosas cada vez más humanas. Por ejemplo en la defensa de los derechos de los pobres y excluidos, respeto por las expresiones religiosas de los pueblos, por su manera de concebir su territorio. También la conexión que tiene por ejemplo la ternura, con la no violencia, incentivando el trabajo en reciprocidad, participación, escucha de demandas justas; con la implementación de servicios para la comunidad ligados al bienestar; su relación con el orden, creando ambientes agradables, creo que la implementación de espacios recreacionales, parques, jardines, arborización, cuidado de las tierras, bosques etc., son opuestos al caos y al desagrado y propician la paz. Poner ternura en lo que se dice, se decide, se hace, genera vida nueva.

No hay espacio vedado para la ternura; el Padre Hubert Lanssier (1998) testimonia que la ternura puede crecer en los lugares más inhóspitos, hasta en la cárcel y añade que el contacto con situaciones límite de la humanidad también moviliza la ternura y la creatividad, porque ante la desesperanza y el dolor brota la llamada a "reinventar, a pesar de ser hombre, los gestos elementales de la maternidad"p.224

La ternura es el corazón de lo humano y vivirla es tejer la relación desde lo esencial. Desde lo esencial siempre surge algo nuevo, porque es fuente de creación. Volver a la ternura temprana, enriquecida por la experiencia nos hará hombres y mujeres nuevas.

\section{Conclusiones}

La dignidad del ser humano requiere el reconocimiento concreto y motivador del amor y la ternura para desarrollarse plenamente, y nosotros tenemos la responsabilidad de comunicar esta ternura por fidelidad a nuestro ser y al ser de los otros.

Hace falta revisar la concepción de Dios que tenemos, porque el Dios que se ha mostrado ha sido a veces, opuesto a la auténtica invocación de ternura que la misma naturaleza humana pide para desarrollarse y alcanzar plenitud.

La ternura como valor moral tiene fuerza histórica capaz de motivar y transformar la sociedad, porque es cuidado, preocupación por el otro, es lucidez para percibir necesidades, es hacerse cargo del otro, es no violencia, fuerza que se involucra con otros, en el dolor humano. 
Vivir con ternura es desplegar el potencial humano de amar, y esto se aprende con la práctica cotidiana de hacer evidente el bien, la verdad y la belleza de las personas y de la naturaleza; de valorar nuestro cuerpo y su expresividad y desarrollando la sensibilidad, la capacidad de sentir con el otro y el asombro ante el misterio.

Como educadores o padres de familia somos alertados hoy por nuevas formas de violencia como la agresión en las aulas (Bulling), o incluso el acoso laboral más al descubierto, urge pues trabajar la ternura vinculada a la propia valoración, en los planes educativos de desarrollo de la personalidad de niños y jóvenes.
La ternura como disposición interna de la acción, como gestos concretos en la relación de personas y pueblos, y compromiso con la creación, se necesita para hacer del mundo la casa humana de cercanía, de presencia cálida, de encuentro, de fe, porque como afirma el poeta:

"Podemos estrechar miles de manos

$$
y \text { quedar solos }
$$

llenas las manos de sensaciones en el borde de la piel:

Podemos estrechar una sola mano y sentir en ella el calor del absoluto"

Benjamín Gonzalez Buelta S.J. Poemas-Atravesar las apariencias 


\section{Referencias}

- Auer, H. (1997). Psicología Humanista Módulos de Psicoterapia. Lima: Universidad Femenina del Sagrado Corazón, UNIFE T. 1

- Boff, L. (1999). Saber Cuidar: Ética de lo humano. Petropolis. Ed. Vozes. http://www.mundosustentavel.com .br/ementa.pdf

- Boff, L. (2003). Del Iceberg al Arca de Noé. Bilbao: Ediciones Sal Terrae

- Erickson, E. (1956). Etapas del Desarrollo social y emocional.

- Fernández Abascal, E (2009). Emociones Positivas. Madrid:. Ediciones Pirámide

- González Buelta, B. (2010). Caminar sobre las aguas. Nueva Cultura, Mística y Ascética. España: Sal Terrae.

- Heidegger, M (1927). Ser y Tiempo. Ed. elect. www:philosophia.co/ Escuela de Filosofía. Universidad ARCI. Mayo 2011

- Lanssiers, H. (1998). Los Dientes del Dragón. Lima: Ediciones COPE 4ta ed.

- Macías Vadaler, G. (2008). Emociones y Sentimientos. México: Trillas.
- Maya, A. (2003). Conceptos Básicos para una Pedagogía de la Ternura. Bogotá: Ecoe ediciones.

- Medina G. C (2011). II Congreso Regional de Educación Infantil.Bucaramanga - Colombiawww.encolombia.com/pediatria353 00gramatica.htm.

- Restrepo, L. (1997). El derecho a la ternura. Colombia: Arago Editores.

- Scavino, D. (1999). La Filosofía Actual. Pensar sin certezas. Argentina: Editorial Paidós.

- Seligman, M. (2005). Niños Optimistas. Barcelona. www.facultyfp.salisbury.edu/iewhite /Optimistic\%20Child.doc. Google 27-05-2011

- II Taller Latinoamericano de Educación Formal (1998). El espíritu educador del Sagrado Corazón en las instituciones educativas de América Latina y el Caribe. Lima.

Universidad Femenina del Sagrado Corazón (2009). Carta de Santa Magdalena Sofía Barat a los Educadores de Ayer y de Hoy. (Transcripción y selección hecha por las Religiosas del Sagrado Corazón de la Unifé. Lima. 